\title{
Community structure and abundance of bottlenose dolphins Tursiops truncatus in coastal waters of the northeast Gulf of Mexico
}

\author{
Reny B. Tyson ${ }^{1, *}$, Stephanie M. Nowacek ${ }^{1}$, Douglas P. Nowacek ${ }^{1,2}$ \\ ${ }^{1}$ Nicholas School of the Environment and ${ }^{2}$ Pratt School of Engineering, Duke University Marine Laboratory, Beaufort, \\ NC 28516-9721, USA
}

\begin{abstract}
We examined bottlenose dolphin Tursiops truncatus community structure and abundance in the northeast Gulf of Mexico coastal waters stretching from St. Vincent Sound to Alligator Harbor, Florida, USA. Photographic-identification surveys were conducted between May 2004 and October 2006 to gain an understanding of dolphin distribution in this region. Dolphins were distributed year-round throughout the region; however, individual sighting records indicate that 2 parapatric dolphin communities exist. We conducted mark-recapture surveys using photographic-identification techniques to estimate the abundance of dolphins inhabiting the 2 areas these communities reside in: St. Vincent Sound/Apalachicola Bay, western; and St. George Sound/ Alligator Harbor, eastern. Sighting records of individual dolphins from 2004 to 2008 support the existence of 2 communities in these areas; only $3.5 \%$ of distinctive dolphins photographed were seen in both western and eastern areas. The 2 communities differ in their structure: the eastern area supports a more transient population with $45.7 \%$ of distinctive dolphins photographed only once compared with $28.3 \%$ in the west. Independent estimates of abundance $(\mathrm{N}, 95 \% \mathrm{CI}=[\mathrm{low}$, high]) were calculated using the Chapman modification of the Lincoln-Petersen method for June 2007 and for January and February 2008 for the eastern area (242 [141-343], 395 [273-516]) and for the western survey area $(197[130-264], 111$ [71-150]), respectively. Our results serve as a baseline that can be used by the US National Marine Fisheries Service to manage bottlenose dolphins in this region.
\end{abstract}

KEY WORDS: Bottlenose dolphin $\cdot$ Photographic identification $\cdot$ Mark-recapture $\cdot$ Community structure $\cdot$ Abundance

\section{INTRODUCTION}

The coastal and near-shore waters stretching from St. Vincent Sound to Alligator Harbor (SVS-AH) along the northern Gulf coast of Florida, USA (Fig. 1) represent one of the least understood areas of Florida with regard to marine mammal populations, specifically bottlenose dolphins Tursiops truncatus. Additionally, this region represents one of the most productive and anthropogenically undeveloped estuarine systems in the northern hemisphere (Livingston et al.
1998). The only published confirmation that bottlenose dolphins inhabit these waters comes from aerial surveys conducted in 1993, a coarse survey that estimated cetacean abundance throughout the Gulf of Mexico (Blaylock \& Hoggard 1994, Waring et al. 2008). Blaylock \& Hoggard (1994) estimated an abundance of 387 dolphins in this region (coefficient of variation $[\mathrm{CV}]=0.34$ ); however, no systematic surveys for bottlenose dolphins have been completed in SVS-AH since that time. Abundance and community structure of bottlenose dolphins in nearby St. Joseph 


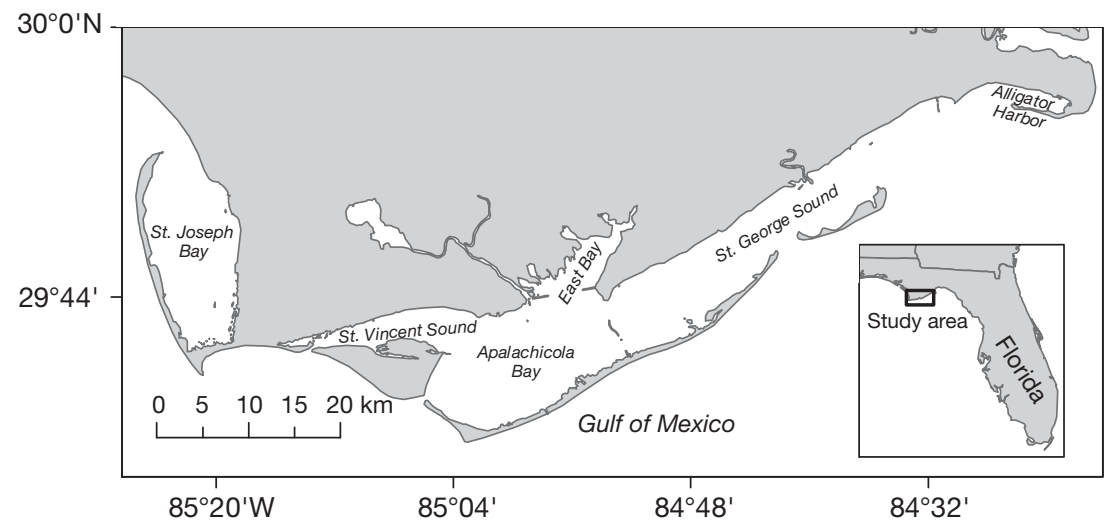

Fig. 1. Coastal and near-shore waters stretching from St. Vincent Sound to Alligator Harbor along the northern Gulf coast of Florida were included in this study. St. Joseph Bay is included for reference
While few dolphins stranded in SVS-AH, these events brought attention to the lack of current and robust information regarding dolphins in these waters. Here we use the results of baseline photo-ID surveys and subsequent markrecapture surveys to describe the community structure of bottlenose dolphins in this region and to estimate their abundance. Understanding the baseline distribution of dolphins in this area will allow managers to assess the impacts to the dolphin population and the ecosystem if and when modifications to the system take place.
Bay, Florida (Fig. 1) have been reported (Balmer et al. 2008), though radio-tracking results from 23 dolphins tagged in St. Joseph Bay indicate very little movement of dolphins between St. Joseph Bay and SVS$\mathrm{AH}$.

Photo-identification (photo-ID) methods, which rely on obtaining a photograph of an individual dolphin's natural markings (such as nicks, notches, and/or scars found along the dorsal fin or peduncle), are widely used in the study of bottlenose dolphins. These natural markings are considered to be longlasting, and they have been used successfully to identify individuals and track them over time (Hammond 1990, Wilson et al. 1999). Using photo-ID methods, researchers have found that bottlenose dolphins are distributed relatively continuously in most parts of their range, although within this continuum range boundaries and discrete communities (i.e. resident dolphins that regularly share large portions of their ranges, exhibit similar distinct genetic profiles, and interact with each other to a much greater extent than with dolphins in adjacent waters; Wells et al. 1987) have been defined (Shane 1980, Irvine et al. 1981, Wells 1986, 1991, Wells et al. 1987, Hansen 1990, Shane 1990, Rossbach \& Herzing 1999, Chilvers \& Corkeron 2003, Lusseau et al. 2005, Fazioli et al. 2006, Balmer et al. 2008, Urian et al. 2009).

In 1999, 2004, and 2005/2006 an unusually high number of dolphin mortalities occurred along the Florida panhandle and more than 300 bottlenose dolphins died; the deaths appear to have been spatially and temporally correlated with blooms of Karenia brevis, a toxin-producing dinoflagellate known to cause red tide (NMFS 2004, Waring et al. 2008).

\section{MATERIALS AND METHODS}

\section{Study area}

The study region (Fig. 1) is largely within the Apalachicola National Estuarine Research Reserve. The region contains approximately $623 \mathrm{~km}^{2}$ of water surface area and includes St. Vincent Sound, Apalachicola Bay, East Bay, St. George Sound, and Alligator Harbor. The exchange dynamics of the waters here are complex with East Bay, St. Vincent Sound, and Apalachicola Bay being highly influenced by the Apalachicola River, while St. George Sound and Alligator Harbor are more influenced by the Gulf of Mexico (Niu et al. 1998). Several barrier islands separate much of the survey region from the Gulf of Mexico including (from west to east) St. Vincent Island, Little St. George Island, St. George Island, and Dog Island.

\section{Survey design}

From May 2004 to October 2006 we conducted boat-based photo-ID surveys throughout the region to build a photo-ID catalog of distinctive dolphins and to determine their distribution (hereafter referred to as baseline surveys). In June 2007 (summer) and January/February 2008 (winter) we implemented mark-recapture techniques to estimate the abundance of dolphins inhabiting the region during these 2 time periods (hereafter referred to as mark-recapture surveys). Based on findings from the 2004 to 2006 baseline surveys 
(see 'Results-Community structure analysis') we hypothesized that there were 2 communities in SVS-AH. Therefore, for the mark-recapture surveys, we divided the region into the 2 survey areas in which the communities appear to reside (eastern and western; Fig. 2). We derived independent estimates of abundance for each survey area and each season using the Chapman modification of the Lincoln-Petersen model (Chapman 1951). Each area was surveyed once to mark dolphins and a second time to recapture them, with the eastern area surveyed before the western area. To ensure that the entire region was sampled uniformly during each sampling period, we surveyed along transect lines that were distributed throughout the region and were chosen randomly on a given survey day (Fig. 2). Individual dolphins were 'marked/captured' by obtaining photographic images of their dorsal fins.

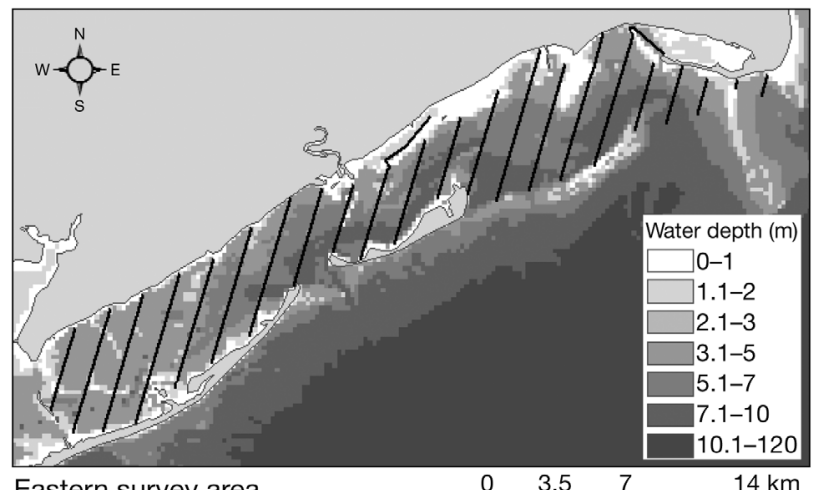

Eastern survey area 3.

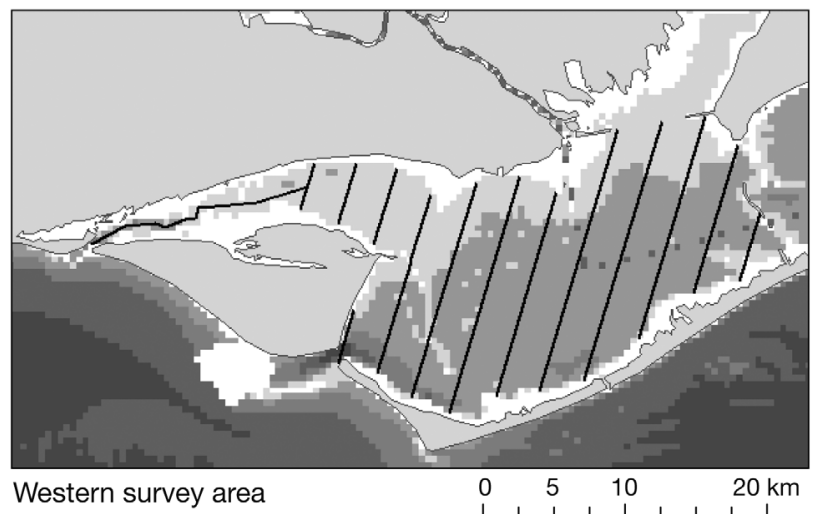

Fig. 2. The study region was divided into 2 survey areas for the mark-recapture surveys; St. George Sound to Alligator Harbor (eastern), and St. Vincent Sound and Apalachicola Bay (western). Transects (bold lines) were spaced $2 \mathrm{~km}$ apart throughout the region (excluding East Bay and Alligator Harbor) and approached the $1 \mathrm{~m}$ bathymetric line along the barrier islands and $2 \mathrm{~m}$ contour line in areas where no barrier islands were present

\section{Field effort}

All surveys (baseline and mark-recapture) were conducted from a $6 \mathrm{~m}$, outboard-powered, centerconsole research vessel, which traveled at the minimum speed allowable to maintain a plane during good sighting conditions (i.e. 10 to 14 knots; Beaufort Sea State $[\mathrm{BSS}] \leq 3)$. Researchers on board included 3 to 4 experienced observers: 1 to 2 photographers, a data recorder, and a boat driver. When a group of dolphins was sighted the boat left the transect line and slowly approached the group. For every encounter with dolphins the GPS position of the animals was recorded; a field estimate was made of the minimum, maximum, and best estimate of number of individuals, number of calves, and number of neonates in the group; and behavioral and environmental data were recorded. A Canon-20D with 70 to $300 \mathrm{~m}$ lens was used to take digital photographs of the dorsal fin and other distinguishing features (e.g. peduncle) of each dolphin in the group. After an attempt to obtain pictures of every individual in the group was made, the boat returned to the location where it had left the transect and continued to follow the predetermined route. As many transects as possible were surveyed on a given day depending on the weather conditions, location of selected transects, and the time of day. Groups of dolphins sighted while not actively surveying along a transect line, e.g. transiting between transects, were noted as being sighted while 'off effort', and the same procedures for obtaining photographs and behavioral information were followed; however, sometimes factors limited how long we could stay with an 'off effort' group (e.g. weather, time of day) to take photographs.

\section{Photographic-identification processes and analysis}

We followed the methods described by Urian et al. (1999) to conduct photo-ID processing and analyses. Dorsal-fin images were cropped (ACDSee 9.0 ${ }^{\mathrm{TM}}$ ), graded independently for photographic quality (clarity, contrast, and angle) and for overall distinctiveness of the fin. Two researchers graded each image to minimize biases, one graded quality and the other graded distinctiveness of fin, and then images were matched to a catalog of pictures previously taken of distinctive dolphins in the region. Photographs of fins in this catalog received unique identification numbers based on the locations of the dolphins' distinctive markings along the trailing edges of their fins. To 
minimize subjectivity and the possibility of making incorrect matches or missing matches altogether, poor-quality photographs and photographs of poorly marked dolphins were not used in the analysis (Friday et al. 2000, 2008, Stevick et al. 2001, Read et al. 2003). To minimize false positive matches, as many distinctive features as possible were used to confirm matches (Scott \& Chivers 1990, Wilson et al. 1999). A second investigator verified every potential match of an individual dolphin from one encounter to another and double-checked the entire catalog for potential matches or mismatches that may have been overlooked.

\section{Community structure analysis}

To assess community structure of dolphins in the region we examined the sighting locations of every distinctive dolphin identified in the region regardless of whether they were sighted during the baseline surveys or the mark-recapture surveys or whether they were sighted while 'on' or while 'off' effort. Sighting locations of each distinctive dolphin were plotted in ArcMap ${ }^{\circledR} 9.3$ and a potential community boundary 'line' was placed every $10 \mathrm{~m}$ between the minimum and maximum longitude values of the entire survey region ( $\mathrm{n}=922$ lines). The number of individual dolphins seen on both sides of each potential community boundary line was recorded (custom written code; R Core Development Team 2008). We assumed that if a particular line represented a community boundary, few if any individuals would be seen on both sides of that line.

\section{Mark-recapture analysis}

Estimates of abundance were derived for dolphins inhabiting the region in the summer of 2007 and the winter of 2008 for each survey area using the Chapman modification of the Lincoln-Petersen model (i.e. data from 2004 to 2006 were not utilized as effort was not standardized; Pollock 1990). This model is valid when there are only 2 sampling occasions and the time between sampling occasions is kept relatively short (Chapman 1951, Seber 1982). Here an initial sample of individuals $\left(n_{1}\right)$ is captured, marked or tagged for future identification, and returned to the population. Later, a second sample of individuals $\left(n_{2}\right)$ is captured, $m_{2}$ of which are marked or tagged. If we assume that the proportion of marked individuals in the second sample is a reasonable estimate of the unknown population proportion, the two can be equated and an estimate of $\tilde{N}$ (population size) can be obtained (Seber 1982).

The Chapman modification of the Lincoln-Petersen model:

$$
\tilde{N}=\frac{\left(n_{1}+1\right)\left(n_{2}+1\right)}{\left(m_{2}+1\right)}-1
$$

requires sampling without replacement (once an animal is captured during the recapture sampling period, it cannot be counted again if recaptured again; Chapman 1951). For each survey period, the sighting histories of distinctive dolphins were separated into the number photographed during the mark occasion $\left(n_{1}\right)$ and the number photographed during the recapture occasion $\left(n_{2}\right)$; sighting histories of dolphins captured while on and while off effort were included in the mark sampling occasion to increase the sample size, while only on-effort sightings were included in the recapture sampling occasion to ensure that they were a random sample (Seber 1982, Williams et al. 2002). The number of distinctive dolphins photographed during both the mark and the recapture occasions was recorded as $m_{2}$. Capture probabilities for each sampling occasion were calculated as:

$$
p_{1}=\frac{m_{2}}{n_{2}}, \quad p_{2}=\frac{m_{2}}{n_{1}}
$$

The Chapman modification of the Lincoln-Petersen model is a bias-adjusted estimator that is conditionally unbiased when $n_{1}+n_{2} \geq \tilde{N}$ (if this condition is not met, $\tilde{N}$ will be negatively biased; Chapman 1951). Approximate model bias was examined for each derived estimate using the equation provided by Robson \& Regier (1964):

$$
\text { Approximate bias }=100 \mathrm{e}^{-\left(n_{1}+1\right)\left(n_{2}+1\right) / N \%} \%
$$

where $N$ is an assumed estimate of population size. Model bias was approximated for values of $N$ ranging from 0 to 1000 and specifically with respect to the value of $N$ derived by Blaylock \& Hoggard (1994) for the SVS-AH region; given the evidence of community structure in SVS-AH, their estimate $(N=387)$ was proportioned by the surface area ratio for each survey area $(N=269.03$ for the eastern and $N=$ 119.97 for the western areas, respectively). The bias of $\tilde{N}$ was deemed to be negligible if the approximate bias was small (<2\%; Robson \& Regier 1964).

If we assume that the probability of capture is independent of whether or not an individual has long lasting marks (Hammond 1990, Williams et al. 1993), we can expand our estimate to include the nondistinc- 
tive population. We achieved this by calculating the ratio $(\theta)$ of distinctive dolphins to total dolphins encountered during the study from all photos that met or exceeded photo quality thresholds. In our study, the variety of temporary skin markings (e.g. tooth rake mark, discoloration) and fin shapes made it possible to distinguish nondistinctive dolphins within a particular sighting. Therefore, $\theta$ was based on the actual number of distinctive versus nondistinctive dolphins encountered during our markrecapture study (Wilson et al. 1999). After summing the number of distinctive and total dolphins encountered the estimate was derived as:

$$
\mathrm{N}=\frac{\tilde{\mathrm{N}}}{\theta}
$$

where $\mathrm{N}=$ the estimated total population size, $\tilde{N}=$ the mark-recapture estimate of the distinctive dolphins, and $\theta=$ the proportion of distinctive dolphins in the population (Williams et al. 1993, Wilson et al. 1999). Variances were calculated using the delta method (Williams et al. 1993):

$$
\operatorname{var}(\mathrm{N})=\mathrm{N}^{2}\left(\frac{\operatorname{var}(\tilde{\mathrm{N}})}{\tilde{\mathrm{N}}^{2}}+\frac{1-\theta}{n \theta}\right)
$$

where $n=$ the total number of dolphins from which $\theta$ was estimated. The $95 \%$ confidence interval (CI) for each estimate was calculated by multiplying the square root of the variance by 1.96 and the standard error distribution (SE) was assumed to be the same as the estimate of the distinctive population estimate (Williams et al. 1993). The coefficient of variation (CV) of $\mathrm{N}$ was calculated by dividing the SE of $\mathrm{N}$ by N (Pollock et al. 1990).

The Lincoln-Petersen estimator assumes that over the course of the study: (1) the population is closed to additions (via birth and immigration) and losses (via death and emigration), (2) marks are neither lost nor overlooked by the investigator, and (3) all animals are equally likely to be captured in each sample (Seber 1982). The validity of these assumptions was examined for each sampling period. The assumption of closure (1) was examined in several ways. First, while a limited number of births and deaths may occur during the sampling period their low probability of occurrence suggests that the assumption of demographic closure is likely met if the study period is kept relatively short (Wells \& Scott 1999, Read et al. 2003). The same is true for immigration and emigration of dolphins to/from the study area but is harder to assess (Otis et al. 1978, Williams et al. 2002, Read et al. 2003). Therefore, sampling periods were kept as short as possible. Discovery curves of identified dolphins over each sampling period and the percentage of recaptures that occurred during the study were examined. Rates of movement between the 2 study areas were also examined and were expected to be minimal, since dolphins that were sighted in both survey areas during the baseline surveys were never sighted in both areas within a $12 \mathrm{~d}$ period.

The Lincoln-Petersen estimator also assumes that all dolphins have an equal probability of capture; however, certain types of heterogeneity are allowed (Seber 1982). For instance, if individuals exhibit heterogeneous capture probabilities but the capture probabilities of an individual in the 2 sampling occasions are completely independent (so dolphins with a relatively high capture probability in the first period do not necessarily have a high capture probability again in the second period), an unbiased estimate of population size can still be derived (Pollock et al. 1990, Williams et al. 2002). If heterogeneity exists such that dolphins with high capture probabilities are more likely captured in the first sample and recaptured in the second sample, the true proportion of dolphins marked in the population will be overestimated and $\mathrm{N}$ will be negatively biased (Pollock et al. 1990). Data resulting from the photographic analyses (e.g. sighting histories and locations) were used to determine whether these assumptions were met.

\section{RESULTS}

\section{Community structure analysis}

We determined community structure using sighting information from every distinctive individual photographically identified from May 2004 to February 2008. During this period we completed 127 surveys and recorded 418 sightings of bottlenose dolphins in SVS-AH (Table 1). We identified 624 individuals by their natural markings and encountered an additional 417 individuals that we considered nondistinctive (nondistinctive dolphins could have been seen more than once). Of the 624 distinctive individuals seen, 374 of them were seen more than once throughout the survey region.

Dolphins were distributed year-round throughout the region, except within East Bay where we had only 2 sightings and Alligator Harbor where we had 0 sightings (however, we did not survey in these waters for the 2007 and 2008 mark-recapture surveys). Of the 374 distinctive dolphins that were seen more than once from May 2004 to February 2008, 
Table 1. Summary of photographic-identification surveys conducted from St. Vincent Sound to Alligator Harbor along the northern Gulf coast of Florida from May 2004 to February 2008

\begin{tabular}{|c|c|c|c|c|c|c|c|c|c|}
\hline Year & Month & $\begin{array}{l}\text { No. of } \\
\text { survey } \\
\text { days }\end{array}$ & $\begin{array}{l}\text { Time } \\
\text { surveyed } \\
\text { (h) }\end{array}$ & $\begin{array}{l}\text { Distance } \\
\text { surveyed } \\
(\mathrm{km})\end{array}$ & $\begin{array}{l}\text { No. of } \\
\text { sightings }\end{array}$ & $\begin{array}{l}\text { Best field } \\
\text { estimate of } \\
\text { dolphins }\end{array}$ & $\begin{array}{c}\text { No. of } \\
\text { dolphins seen } \\
\text { only once }\end{array}$ & $\begin{array}{c}\text { No. of } \\
\text { nondistinctive } \\
\text { dolphins } \\
\text { sighted }\end{array}$ & $\begin{array}{c}\text { No. of } \\
\text { dolphins } \\
\text { positively } \\
\text { identified }\end{array}$ \\
\hline \multirow[t]{4}{*}{2004} & May & 5 & 40.3 & 552.00 & 30 & 289 & 17 & 49 & 165 \\
\hline & Oct & 4 & 25.1 & 285.73 & 12 & 82 & 6 & 12 & 23 \\
\hline & Nov & 5 & 28.4 & 364.90 & 10 & 86 & 9 & 10 & 30 \\
\hline & Dec & 3 & 13.5 & 204.62 & 8 & 53 & 1 & 6 & 28 \\
\hline \multirow[t]{11}{*}{2005} & Jan & 5 & 24.8 & 412.60 & 11 & 62 & 2 & 9 & 34 \\
\hline & Feb & 4 & 18.7 & 284.21 & 8 & 29 & 0 & 5 & 20 \\
\hline & Mar & 8 & 34.5 & 598.28 & 12 & 63 & 6 & 6 & 47 \\
\hline & Apr & 1 & 4.3 & 85.12 & 2 & 4 & 0 & 4 & 0 \\
\hline & May & 6 & 27.3 & 571.55 & 8 & 54 & 3 & 9 & 38 \\
\hline & Jun & 7 & 27.3 & 485.62 & 11 & 47 & 1 & 11 & 28 \\
\hline & Jul & 1 & 7.1 & 150.57 & 2 & 13 & 0 & 2 & 8 \\
\hline & Aug & 2 & 13.7 & 266.83 & 3 & 20 & 0 & 4 & 15 \\
\hline & Sep & 2 & 12.6 & 256.95 & 3 & 26 & 0 & 2 & 17 \\
\hline & Oct & 3 & 18.6 & 376.26 & 9 & 56 & 5 & 8 & 37 \\
\hline & Nov & 1 & 7.4 & 89.57 & 5 & 22 & 1 & 7 & 11 \\
\hline \multirow[t]{12}{*}{2006} & Jan & 2 & 6.3 & 147.40 & 3 & 19 & 1 & 3 & 12 \\
\hline & Feb & 6 & 36.5 & 666.85 & 31 & 119 & 9 & 18 & 78 \\
\hline & Mar & 2 & 13.7 & 215.35 & 9 & 60 & 2 & 11 & 42 \\
\hline & Apr & 3 & 16.8 & 280.45 & 12 & 88 & 16 & 13 & 55 \\
\hline & May & 4 & 22.7 & 454.31 & 13 & 83 & 2 & 10 & 61 \\
\hline & Jun & 4 & 25.0 & 462.29 & 12 & 92 & 6 & 16 & 53 \\
\hline & Jul & 4 & 15.6 & 259.18 & 9 & 57 & 3 & 9 & 41 \\
\hline & Aug & 2 & 7.6 & 147.18 & 7 & 40 & 0 & 7 & 33 \\
\hline & Sep & 1 & 5.3 & 109.56 & 2 & 20 & 0 & 5 & 15 \\
\hline & Oct & 6 & 50.6 & 736.52 & 31 & 201 & 21 & 36 & 114 \\
\hline & Nov & 1 & 6.1 & 95.32 & 5 & 23 & 1 & 1 & 20 \\
\hline & Dec & 1 & 5.7 & 110.57 & 4 & 18 & 0 & 6 & 11 \\
\hline 2007 & Jun & 17 & 99.6 & 1679.77 & 61 & 417 & 32 & 70 & 248 \\
\hline \multirow[t]{2}{*}{2008} & Jan & 14 & 63.4 & 1207.25 & 66 & 394 & 31 & 54 & 266 \\
\hline & Feb & 3 & 17.8 & 399.33 & 19 & 95 & 3 & 14 & 62 \\
\hline Totals & & 127 & 696.1 & 11956.14 & 418 & 2632 & 178 & 417 & 1612 \\
\hline
\end{tabular}

only 22 of them were seen in both the eastern survey area (i.e. St. George Sound to Alligator Harbor) and the western survey area (i.e. St. Vincent Sound and Apalachicola Bay). This demarcation of community boundaries is seen in Fig. 3; the number of distinctive dolphins that were seen on both sides of a putative community boundary line was the lowest along several shoals and oyster bars that topographically separate the 2 survey areas. Given the separation between the communities, the sightings of all the dolphins were examined separately for the 2 areas in which these 2 communities reside.

The discovery curves for the 2 survey areas (Fig. 4) reveal that new distinctive dolphins were continually seen in the survey region from May 2004 to February 2008 but that the rate of sighting new dolphins over time was greater in the eastern area than in the western area. The sighting frequencies of individuals also differed between the 2 survey areas (Fig. 5): $45.7 \%$ of distinctive individuals seen in the eastern area were seen only once compared to $28.3 \%$ of individuals in the western area (this is excluding the 22 individuals seen in both study areas). In addition, the dolphins inhabiting the western survey area exhibited higher patterns of site fidelity than those in the eastern survey area; mean sighting frequencies for distinctive dolphins were 2.93 ( $\mathrm{SD}=1.86$ ) for individuals seen in the west compared to 2.47 ( $\mathrm{SD}=1.96)$ for individuals seen in the east (2-sample $t$-test, $\mathrm{p}=0.0085)$. Also, a larger \% of dolphins were seen in multiple years and multiple seasons in the western survey area than in the eastern survey area (Fig. 6), and the density of 


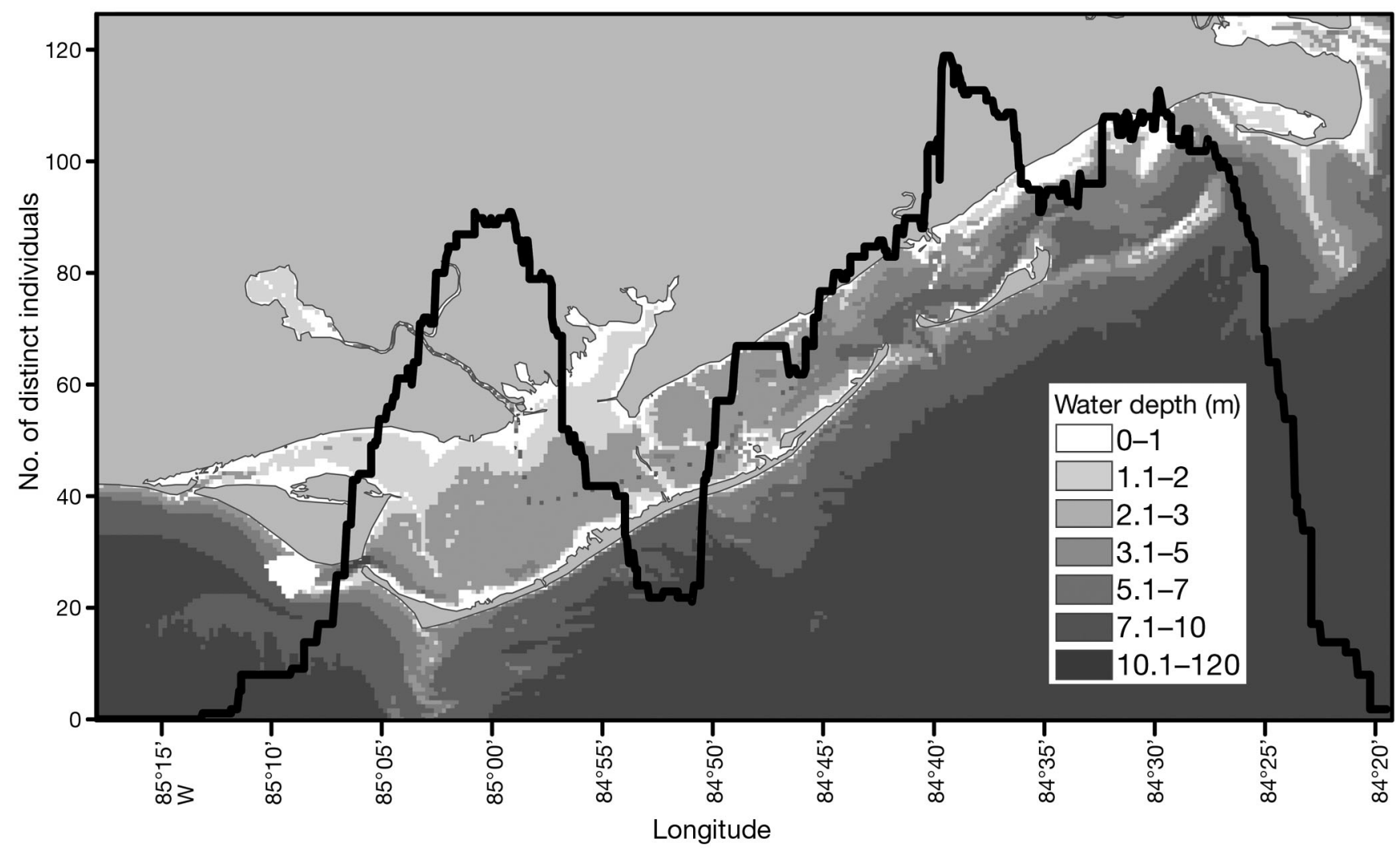

Fig 3. Tursiops truncatus. The number of distinctive bottlenose dolphins seen on both sides of a potential community boundary line (i.e. number of distinctive dolphins overlapping). Potential community boundary lines were placed every $10 \mathrm{~m}$ between the minimum and maximum longitude values (custom written code; R Core Development Team 2008). If a particular line represented a community boundary, few if any individuals would be seen on both sides of that line. A community boundary demarcation exists between $84^{\circ} 50^{\prime}$ and $84^{\circ} 54^{\prime} \mathrm{W}$ as seen by the bimodal distribution in the number of distinctive dolphins overlapping in the region. Note that several shoals and oyster bars stretch longitudinally across the region at this boundary

dolphins seen only once in both survey areas was higher near openings and passes to the Gulf of Mexico than it was within the region.

\section{Estimates of abundance}

\section{Validation of assumptions}

Violations of assumptions of closed-population models were examined for each derived estimate. The assumption of demographic closure was met since the surveys were conducted during a 7 to $19 \mathrm{~d}$ period. While a limited number of deaths may have occurred during the sampling period, their low probability of occurrence suggests that the assumption of demographic closure was met or the number was sufficiently small as to have negligible effects (Wells \& Scott 1999, Read et al. 2003). In addition, births would have likely been noticed (observations of neonates with fetal folds; Mann \& Smuts 1999) and thus would have been included in the estimate of the non-distinctive population. The assumption of geographic closure was more difficult to assess, although movement between the 2 survey areas during the mark-recapture surveys was minimal (only $2.21 \%$ of distinctive dolphins captured during the markrecapture study were seen in both survey areas), and $17.16 \%$ of distinctive dolphins in the east and $26.85 \%$ in the west were sighted both seasons. Discovery curves (Fig. 7), the number of days each survey was completed in, and the $\%$ of dolphins recaptured during the survey were examined to determine whether the assumption of geographic closure was met for each mark-recapture model independently (see last 2 subsections in 'Results'). If the geographic closure assumption was violated and emigration and immigration did occur, $\mathrm{N}$ is only valid for the capture sampling occasion and not for the entire survey period (Robson \& Regier 1964, Seber 1982).

Mark-loss was deemed to be minimal as individual dolphins were identified strictly by marks (e.g. nicks and notches along the trailing edge of the dorsal fin) that are considered long-lasting and potentially per- 


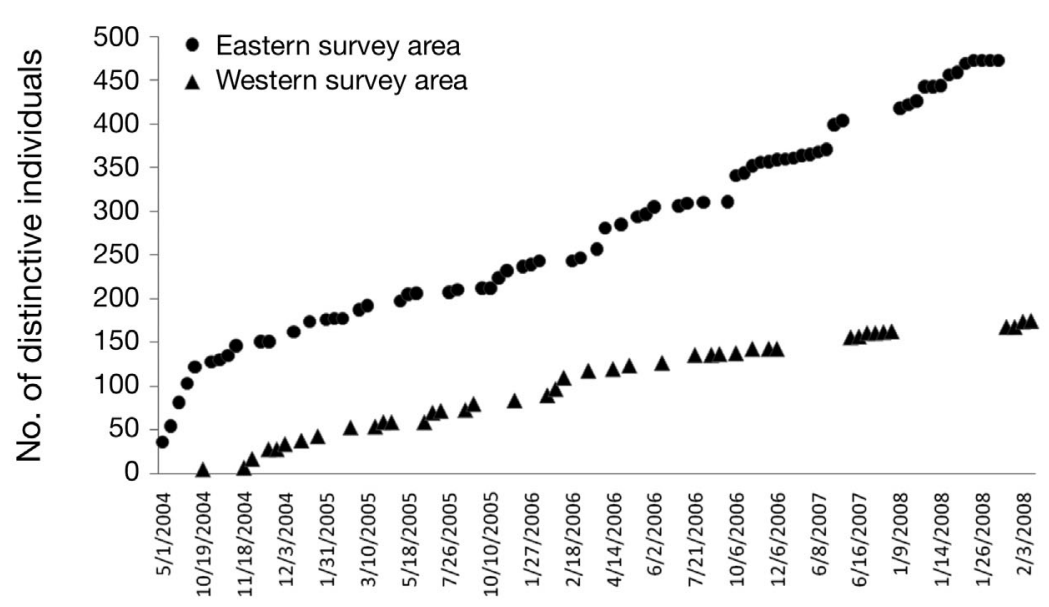

Date surveyed $(\mathrm{m} / \mathrm{d} / \mathrm{y})$

Fig. 4. Tursiops truncatus. Discovery curves of distinctive dolphins captured in the eastern and western survey areas between May 2004 and February 2008 (i.e. change in time of new distinctive dolphins identified). Days where there are no points are not necessarily true zeros; they may represent days in which no surveys were completed

probability of obtaining a useable photograph of each individual so that some dolphins had a higher probability of being caught than other dolphins (Seber 1982, Hammond 1986, Williams et al. 2002). Heterogeneity in capture probabilities was only apparent in the western study conducted in the winter (see 'Western survey area', below). Otherwise, the locations of sightings for all survey areas and seasons were examined and were found to be distributed throughout the region and varied in location. Therefore, the capture probabilities of an individual in the 2 sampling occasions appeared to be independent of each other, suggesting that the respective derived estimates of abundance are unbiased.

\section{Model bias}

manent (Hammond 1990, Lockyer \& Morris 1990, Wilson et al. 1999, Friday et al. 2000, Whitehead et al. 2000). Additionally, because this study took place over a short period of time ( 7 to $19 \mathrm{~d}$ ) it was unlikely that changes occurred or if they did that they went unnoticed (Otis et al. 1978, Williams et al. 2002). Finally, marks were not likely to be overlooked as only distinctive dolphins from high to intermediate quality photos were used to generate estimates. Additionally, a second investigator confirmed all matches and examined the catalog for missed matches.

The assumption that all dolphins within a sampling occasion will have equal probability of being detected may have been violated if our behavior in the field or the behavior of the dolphins affected the

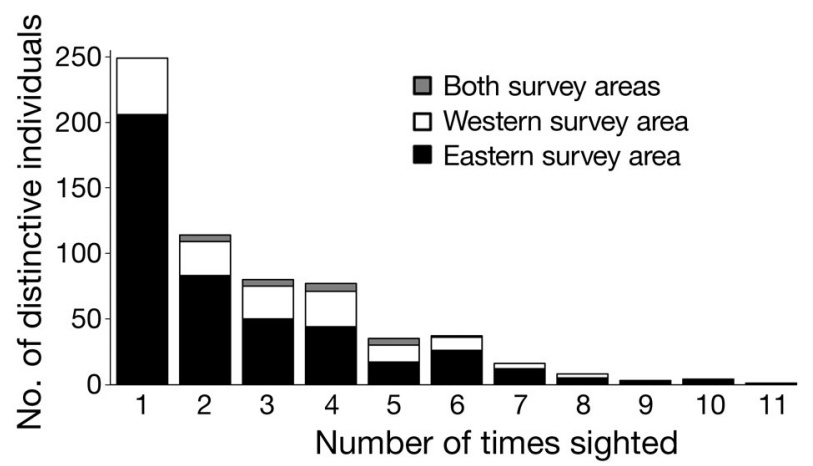

Fig. 5. Tursiops truncatus. Sighting frequencies of distinctive dolphins photographed in the eastern survey area $(n=450)$, in the western survey area $(\mathrm{n}=152)$, and in both survey areas $(n=22)$
Data, discovery curves, and derived estimates of abundance resulting from the mark-recapture surveys conducted in the summer of 2007 and the winter of 2008 are shown in Table 2 and Figs. 7 \& 8. Approximate model bias was negligible $(<2 \%)$ for all surveys with respect to the value of $N$ derived by Blay-
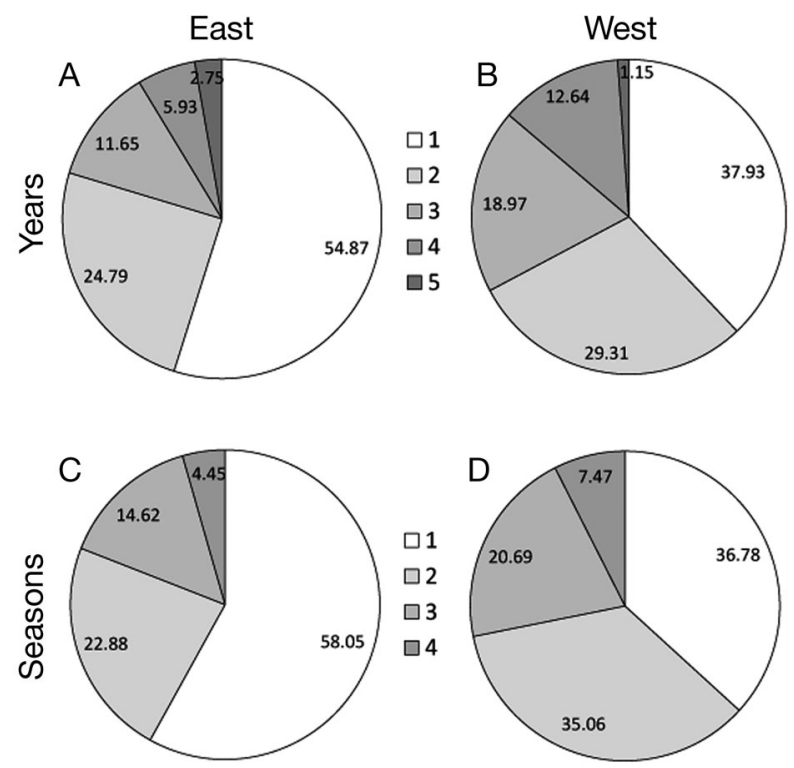

Fig. 6. Tursiops truncatus. Percentage of distinctive dolphins seen in multiple years ( 1 to 5 ) and in multiple seasons (i.e. number of seasons 1 to 4 , not specific seasons) in the eastern and western survey areas, respectively 


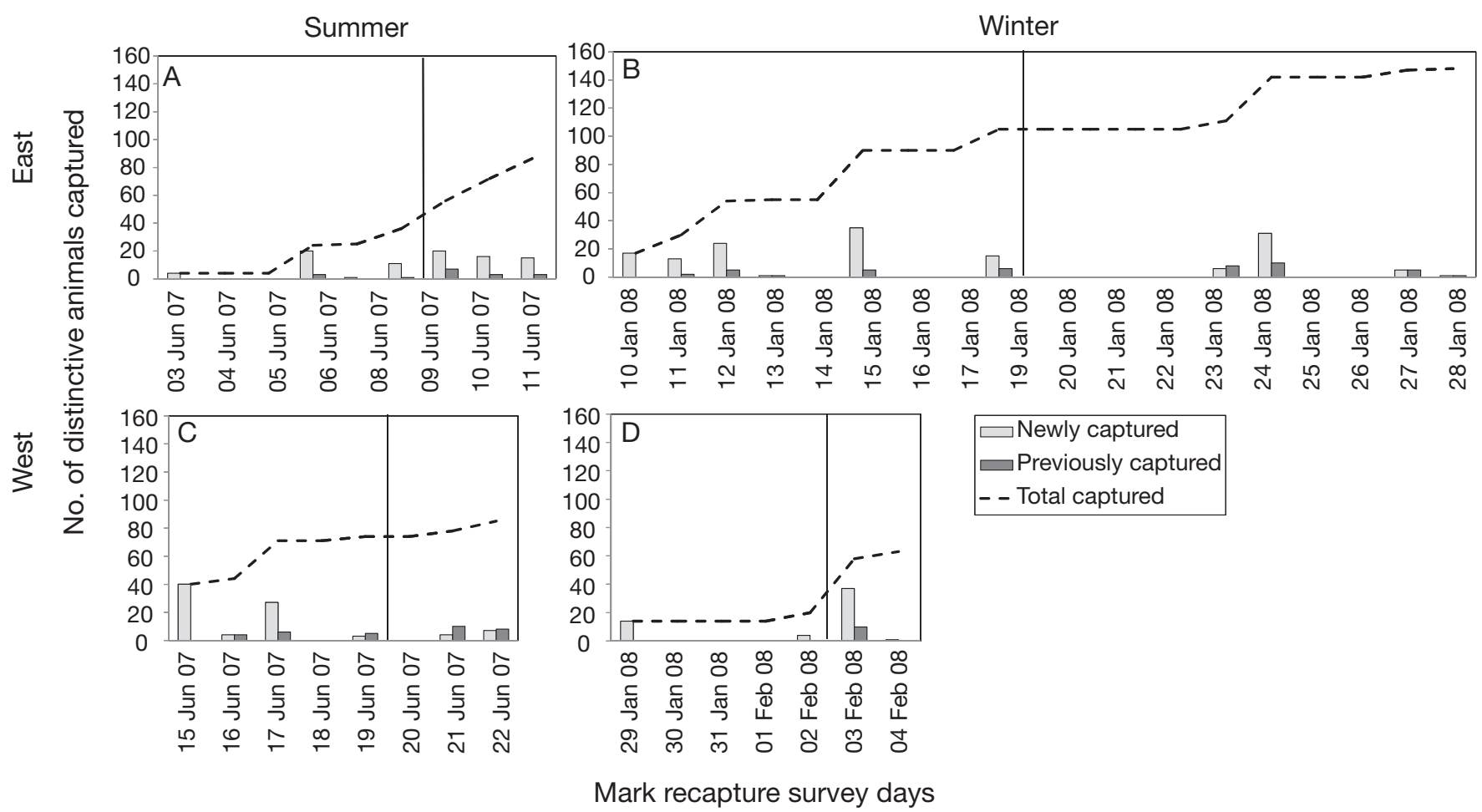

Fig. 7. Tursiops truncatus. Discovery curves of distinctive dolphins captured during each mark-recapture sampling occasion: (A) east summer, (B) east winter, (C) west summer, and (D) west winter. Vertical lines represent the demarcation between mark (to the left) and capture (to the right) sampling occasions

lock \& Hoggard (1994) for the SVS-AH region proportioned by the surface area ratio for each survey area $(N=269.03$ for the eastern and $N=119.97$ for the western areas, respectively) (Fig. 9).

\section{Eastern survey area}

In the summer, the assumption of closure was likely met as $16.09 \%$ of animals were recaptured during the $9 \mathrm{~d}$ study (Table 2). However, because the discovery curve did not asymptote (Fig. 7A), we can- not determine if the population was truly closed. Therefore, we suggest that our derived estimate $(\mathrm{N}$, $95 \% \mathrm{CI}=$ [low, high]) of 242 (141 to 343 ) is only valid for the capture sampling occasion (June 9 to 13, 2007) (Table 2, Fig. 8).

In the winter, the assumption of closure was met (Table 2): during the $19 \mathrm{~d}$ study, $25.00 \%$ of animals were captured more than once, and the discovery curve was approaching an asymptote near the end of the study (Fig. 7B). The derived estimate of abundance for the eastern survey area for January 10 to 26, 2008 is 395 (273 to 516) (Table 2, Fig. 8).

Table 2. Number of survey days; \% of dolphins captured more than once; dolphins marked $\left(n_{1}\right)$, captured $\left(n_{2}\right)$, recaptured $\left(m_{2}\right)$, and associated capture probabilities $\left(p_{1}\right.$ and $\left.p_{2}\right)$; abundance estimate of distinctive population $(\tilde{N})$; mark/distinctiveness rates $(\theta)$; abundance estimate and upper and lower bounds of the $95 \%$ confidence interval of the distinctive and nondistinctive dolphins $(N)$; and associated standard error values (SE) and coefficients of variation values (CV) calculated for each markrecapture survey

\begin{tabular}{|c|c|c|c|c|c|c|c|c|c|c|c|}
\hline $\begin{array}{l}\text { Study } \\
\text { area }\end{array}$ & Season & $\begin{array}{l}\text { No. of } \\
\text { survey } \\
\text { days }\end{array}$ & $\begin{array}{c}\text { \% of } \\
\text { dolphins } \\
\text { recaptured }\end{array}$ & $n_{1}\left(p_{1}\right)$ & $n_{2}\left(p_{2}\right)$ & $m_{2}$ & $\tilde{N}$ & $\theta$ & $\begin{array}{l}\mathrm{N} \text { (upper and } \\
\text { lower bounds } \\
\text { of the } 95 \% \mathrm{CI} \text { ) }\end{array}$ & $\mathrm{SE}$ & $\mathrm{CV}$ \\
\hline \multirow[t]{2}{*}{ East } & Summer & 9 & 16.09 & $36(0.18)$ & $62(0.31)$ & 11 & 193.25 & 0.80 & $242(141-343)$ & 51.61 & 0.21 \\
\hline & Winter & 19 & 25.00 & $105(0.32)$ & $64(0.20)$ & 21 & 312.18 & 0.79 & $395(273-516)$ & 62.02 & 0.16 \\
\hline \multirow{2}{*}{ West } & Summer & 8 & 29.41 & $74(0.54)$ & $24(0.18)$ & 13 & 132.93 & 0.67 & 197 (130-264) & 34.07 & 0.17 \\
\hline & Winter & 7 & 17.86 & $18(0.21)$ & $48(0.56)$ & 10 & 83.64 & 0.76 & $111(71-150)$ & 20.26 & 0.18 \\
\hline
\end{tabular}




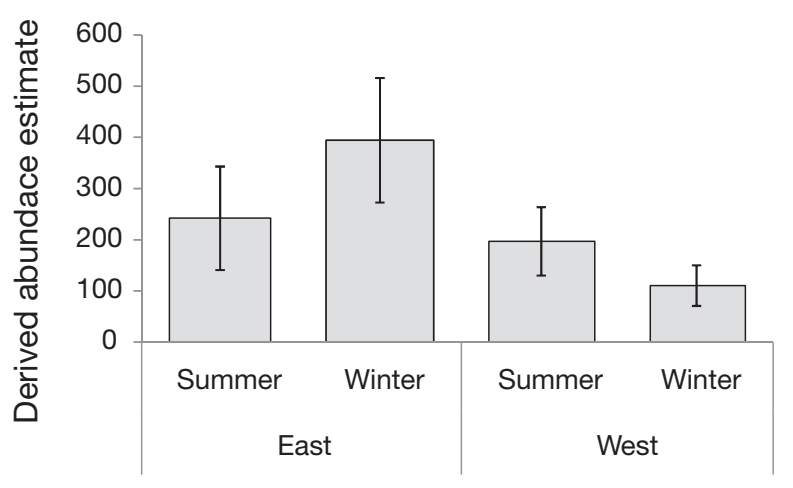

Survey area and season

Fig. 8. Tursiops truncatus. Estimates of dolphin abundance (error bars represent the upper and lower bounds of the $95 \%$ confidence intervals) derived from the Chapman modification of the Lincoln-Petersen model for each survey area and season

\section{Western survey area}

In the summer, the assumption of closure was met as $29.41 \%$ of dolphins were captured more than once during the $8 \mathrm{~d}$ study, and near the end of the study more previously caught dolphins were captured than newly caught dolphins (Table 2, Fig. 7C).
The derived estimate of abundance for the western survey area from June 15 to 22, 2007 was 197.05 (130 to 264).

In the winter, heterogeneity in capture probabilities may have been introduced as a result of favorable sighting conditions that occurred on February 3 , $2008(\mathrm{BSS}=0)$. The likelihood of capturing dolphins may have been higher on this day because the sighting conditions were ideal (i.e. flat seas, clear skies, little wind). In addition, immigration and/or emigration may have occurred, as we cannot determine whether the assumption of closure was met; while $17.86 \%$ of dolphins were captured more than once during the $7 \mathrm{~d}$ study, the discovery curve does not reach an asymptote near the end of the study (Table 2, Fig. 7D). We argue, however, that because the study was conducted in only $7 \mathrm{~d}$, movement into and out of the area was likely minimal. Thus, because the capture probabilities during the capture sampling occasion may have been inflated due to extremely favorable sighting conditions and because the population may not have been closed, the derived estimate of abundance of 111 (71 to 150) is only valid for the capture sampling occasion February 3 to 4, 2008 (Table 2, Fig. 8; Robson \& Regier 1964, Seber 1982).

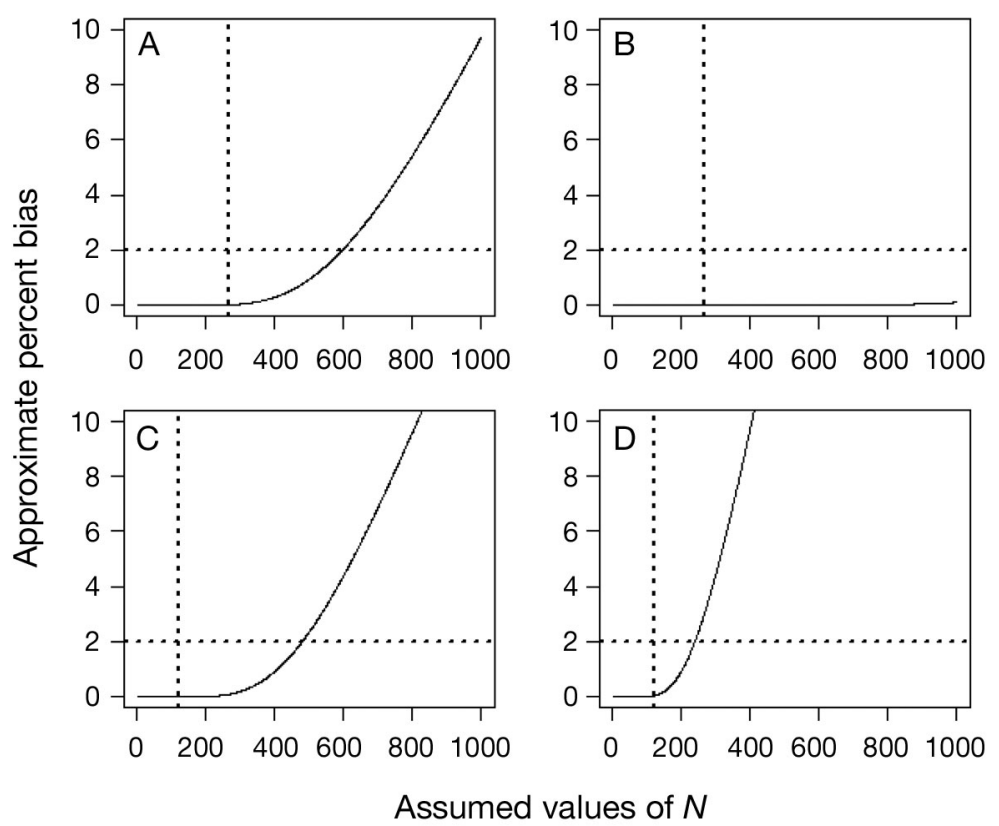

Fig. 9. Approximate model bias for each derived estimate for assumed values of $N$ (Robson \& Regier 1964): (A) east summer, (B) east winter, (C) west summer, and (D) west winter. The bias of $\tilde{N}$ was deemed to be negligible if the approximate bias was small $(<2 \%$, horizontal dotted line; Robson \& Regier 1964). The vertical dotted line represents the proportionate estimate derived by Blaylock \& Hoggard (1994): $N=269.03$ for the eastern and $N=119.97$ for the western areas, respectively

\section{DISCUSSION}

Our results suggest that there are 2 parapatric communities of bottlenose dolphins inhabiting SVS-AH; only $3.5 \%$ of distinctive dolphins identified in the region were seen in both St. Vincent Sound/Apalachicola Bay (western area) and St. George Sound/Alligator Harbor (eastern area, Fig. 2) over the 4 yr this study was conducted. This is similar to findings documented by Urian et al. (2009), who found that most communities of dolphins in Tampa Bay, Florida, showed relatively little overlap in their ranges. The separation in SVS-AH appears to be supported by a natural boundary line; the boundary we found to be most appropriate in delineating these communities includes several shoals and oyster bars, which might act as a natural barrier separating the 2 communities (Fig. 3). More photo-ID surveys need to be completed in SVS-AH to determine if a more appropriate boundary exists and/or if finer-scale community 
structure is present. For instance, sympatric communities may exist within both the eastern and western areas; dolphin communities in Moreton Bay (Queensland, Australia; Chilvers \& Corkeron 2003), the Moray Firth (Scotland, UK; Lusseau et al. 2005), and Tampa Bay (Urian et al. 2009) had significant overlap in their range. In addition, more research is needed to understand why such differences in ranging patterns may exist (Urian et al. 1999).

The 2 communities differ in their structure and abundance. The eastern survey area supports a largely transient population; $45.7 \%$ of distinctive dolphins photographed were seen only once in the $4 \mathrm{yr}$ of photo-ID effort conducted in the area. The western survey area, while still supporting some transient dolphins $(28.3 \%$ of distinctive dolphins photographed were seen once), appears to support a population that exhibits higher site-fidelity patterns than dolphins seen in the east (Fig. 6). This may be a result of the eastern area being more accessible to other coastal dolphins from offshore waters as it is more open to the Gulf of Mexico. The low sighting rates in both survey areas, however, limit us from making inferences regarding home range or site fidelity patterns by individuals in this region (Urian et al. 2009). In nearby St. Joseph Bay (Fig. 1), Balmer et al. (2008) sighted several dolphins over 30 times and suggested that St. Joseph Bay supports a year-round resident population with transient visitors to the Bay in the spring and autumn. Further research is needed in order to determine if resident communities inhabit each survey area, the source of transient dolphins, and why dolphins inhabiting these areas exhibit different distribution patterns and community structure than dolphins found in other estuarine or coastal environments (e.g. St. Joseph Bay).

The abundance estimates we considered to be most appropriate for each survey for the time period sampled were different for each survey area and season (Table 2, Fig. 8; note that these estimates only provide a 'snapshot' of the population at a given point in space and time, and we make no explicit assumption as to how these estimate relate to the total population to which these dolphins belong; Otis et al. 1978, Seber 1982, Urian et al. 1999). It may be suggested that the estimates derived for the eastern area are positively biased due to the high number of transient dolphins sighted in the eastern survey area over the 4 yr during which we have been surveying the region. We argue, however, that during the mark-recapture sampling periods the populations were essentially geographically closed and further stress that our estimates are only applicable to the dolphins inhabiting the region during the sampling periods. While our results suggest that there were seasonal variations in abundance in both survey areas, additional survey effort should be conducted to examine potential annual variability.

We were limited in our attempt to estimate bottlenose dolphin abundance in SVS-AH. First, we were unable to apply open population models to estimate abundance (e.g. Jolly-Seber) as these models have low precision when there are few recaptures (Pollock et al. 1990). Because we had low resight rates of individual dolphins during the baseline surveys, we chose to survey the region intensively in a short amount of time so that we could apply closedpopulation models. Second, the region is very large (623 $\mathrm{km}^{2}$ of water surface area), and therefore it is logistically difficult to survey multiple times in a short period of time. This inhibited our ability to survey each area more than twice in a season, and therefore we were not able to use other models that permit the relaxation of one or more of the aforementioned assumptions of closed mark-recapture models (these require 3 or more sampling occasions; Seber 1982). Even when all attempts to be cautious are made and the assumptions appear to be met, the Petersen estimate may be biased (Seber 1982). Thus, while our estimates may have some associated biases, the surveys were systematically conducted, the confidence intervals demonstrate the estimates are robust, and they are representative of the 2 communities.

Our results provide new insights regarding bottlenose dolphins in SVS-AH, principally the existence of 2 parapatric communities and systematic abundance estimates, which, to date, have been completely lacking, and our methods can be applied to other estuarine and/or coastal communities of bottlenose dolphins faced with similar changes and threats to their habitats. For example, an unusual mortality event would likely affect the inhabitants of the western survey area more severely than the inhabitants of the eastern survey area (due to the nature of their site fidelity and transient patterns). As top predators, bottlenose dolphins can strongly influence or be influenced by the structure and abundance of other commercially important species in these waters. Consequently, changes in their abundance and distribution can potentially indicate modifications to the ecosystem and/or have significant top-down effects. In addition, our findings are critical for the US Marine Mammal Stock Assessment Reports (e.g. Waring et al. 2008) and can aid authorities in managing dolphins in this region if/when changes to the productivity and structure of the ecosystem occur. 
Acknowledgements. Thank you to K. Urian, R. Wells, W. Dewar, J. Chanton, L. Motta, B. Balmer, B. Pine, K. Pollock, L. Thorne, C. Curtice, A. Rycyk, everyone who assisted in the field, and the Florida State University Marine Lab. Funds for this project were provided by the Florida State University Department of Oceanography and Harbor Branch Oceanography Institute Protect Wild Dolphins Grants 2004-06 and 2005-12. Data were collected under NMFS General Authorization No. 1055-1732.

\section{LITERATURE CITED}

Balmer BC, Wells RS, Nowacek SM, Nowacek DP, and others (2008) Seasonal abundance and distribution patterns of common bottlenose dolphins (Tursiops truncatus) near St. Joseph Bay, Florida, USA. J Cetacean Res Manag 10:157-167

Blaylock RA, Hoggard W (1994) Preliminary estimates of bottlenose dolphin abundance in southern U. S. Atlantic and Gulf of Mexico continental shelf waters. Report No. NMFS-SEFSC-356, NOAA, Miami, FL

Chapman DG (1951) Some properties of the hypergeometric distribution with application to zoological sample censuses. Univ Calif Publ Stat 1:131-160

Chilvers BL, Corkeron PJ (2003) Abundance of indopacific bottlenose dolphins, Tursiops truncatus, off Point Lookout, Queensland, Australia. Mar Mamm Sci 19:85-95

Fazioli KL, Hofmann S, Wells RS (2006) Use of Gulf of Mexico coastal waters by distinct assemblages of bottlenose dolphins (Tursiops truncatus). Aquat Mamm 32:212-222

> Friday N, Smith TD, Stevick PT, Allen J (2000) Measurement of photographic quality and individual distinctiveness for the photographic identification of humpback whales, Megaptera novaeangliae. Mar Mamm Sci 16:355-374

Friday NA, Smith TD, Stevick PT, Allen J, Fernald T (2008) Balancing bias and precision in capture-recapture estimates of abundance. Mar Mamm Sci 24:253-275

Hammond PS (1986) Estimating the size of naturally marked whale populations using capture-recapture techniques. Rep Int Whal Comm Spec Issue 16:253-282

Hammond PS (1990) Capturing whales on film: estimating cetacean population parameters from individual recognition data. Mammal Rev 20:17-22

Hansen LJ (1990) California coastal bottlenose dolphins. In: Leatherwood S, Reeves RR (eds) The bottlenose dolphin. Academic Press, San Diego, CA, p 403-420

Irvine AB, Scott MD, Wells RS, Kaufmann JH (1981) Movements and activities of the atlantic bottlenose dolphin, Tursiops truncatus, near Sarasota, Florida. Fish Bull US 79:671-688

> Livingston RJ, McGlynn SE, Niu X (1998) Factors controlling seagrass growth in a gulf coastal system: water and sediment quality and light. Aquat Bot 60:135-159

Lockyer CH, Morris RJ (1990) Some observations on wound healing and persistence of scars in Tursiops truncatus. Rep Int Whal Comm Spec Issue 12:113-118

Lusseau DB, Wilson B, Hammond PS, Grellier K, and others (2005) Quantifying the influence of sociality on population structure in bottlenose dolphins. J Anim Ecol 75: 14-24 Medline

Mann J, Smuts B (1999) Behavioral development in wild bottlenose dolphin newborns (Tursiops sp.). Behaviour 136: 529-566
Niu XF, Edmistion HL, Bailey GO (1998) Time series models for salinity and other environmental factors in the Apalachicola estuarine system. Estuar Coast Shelf Sci 46: 549-563

NMFS (National Marine Fisheries Service) (2004) Interim report on the bottlenose dolphin (Tursiops truncatus) unusual mortality event along the panhandle of Florida March-April 2004. Available from: NMFS, Southeast Fisheries Science Center, 75 Virginia Beach Dr., Miami, FL 33149 and at http://www.nmfs.noaa.gov/pr/health/ mmume/event2004.htm

Otis DL, Burnham KP, White GC, Anderson DR (1978) Statistical inference from capture data on closed animal populations. Wildl Monogr 62:1-135

Pollock KH, Nichols JD, Brownie C, Hines JE (1990) Statistical inference for capture-recapture experiments. Wildl Monogr 107:1-97

R Core Development Team (2008) R: a language and environment for statistical computing. $\mathrm{R}$ foundation for statistical computing, Vienna. http://www.R-project. org

Read AJ, Urian KW, Wilson B, Waples DM (2003) Abundance of bottlenose dolphins in the bays, sounds and estuaries of North Carolina. Mar Mamm Sci 19:59-73

Robson DS, Regier HA (1964) Sample size in Petersen markrecapture experiments. Trans Am Fish Soc 93:215-226

Rossbach KA, Herzing DL (1999) Inshore and offshore bottlenose dolphin (Tursiops truncatus) communities distinguished by association patterns near Grand Bahama Island, Bahamas. Can J Zool 77:581-592

Scott MD, Chivers SJ (1990) Distribution and herd structure of bottlenose dolphins in the eastern tropical ocean. In: Leatherwood S, Reeves RR (eds) The bottlenose dolphin. Academic Press, San Diego, CA, p 235-244

Seber GAF (1982) The estimation of animal abundance and related parameters, 2nd edn. Griffin, London

Shane SH (1980) Occurrence, movements, and distribution of bottlenose dolphin, Tursiops truncatus, in southern Texas. Fish Bull 78:593-601

Shane SH (1990) Behavior and ecology of the bottlenose dolphin at Sanibel Island, Florida. In: Leatherwood S, Reeves RR (eds) The bottlenose dolphin. Academic Press, San Diego, CA, p 245-265

Stevick PT, Palsbøll PJ, Smith TD, Bravington MV, Hammond PS (2001) Errors in identification using natural markings: rates, sources, and effects on capturerecapture estimates of abundance. Can J Fish Aquat Sci 58:1861-1870

Urian KW, Hohn AA, Hansen LJ (1999) Status of the photoidentification catalog of coastal bottlenose dolphins of the western north Atlantic: report of a workshop of catalog contributors. NOAA Technical Memorandum NMFSSEFSC-425, US Department of Commerce, Beaufort, NC

Urian KW, Hoffmann S, Wells RS, Read AJ (2009) Fine-scale population structure of bottlenose dolphins (Tursiops truncatus) in Tampa Bay, Florida. Mar Mamm Sci 25: 619-638

Waring GT, Josephson E, Fairfield-Walsh CP, Maze-Foley K (2008) U.S. Atlantic and Gulf of Mexico marine mammal stock assessments. Report No. NMFS-NE-201, NOAA, Northeast Fisheries Science Center, Woods Hole, MA

Wells RS (1986) Population structure of bottlenose dolphins: behavioral studies along the central west coast of Florida. Report No. 45-WCNF-5-00366, National Marine Fisheries Service, Southeast Fisheries Center

Wells RS (1991) The role of long-term study in understand- 
ing the social structure of a bottlenose dolphin community. In: Pryor K, Norris KS (eds) Dolphin societies: discoveries and puzzles. University of California Press, Berkley, CA, p 199-225

Wells RS, Scott MD (1999) Bottlenose dolphin Tursiops truncatus (Montagu, 1821). In: Ridgway SH, Harrison R (eds) Handbook of marine mammals, Vol 6, the second book of dolphins and porpoises. Academic Press, San Diego, CA, p 137-182

Wells RS, Scott MD, Irvine AB (1987) The social structure of free-ranging bottlenose dolphins. In: Genoways $\mathrm{H}$ (ed) Current mammalogy, Vol 1. Plenum Press, New York, p 247-305

Whitehead H, Christal J, Tyack PL (2000) Studying cetacean social structure in space and time: innovative

Editorial responsibility: Matthias Seaman,

Oldendorf/Luhe, Germany techniques. In: Mann J, Connor RC, Tyack PL, Whitehead $\mathrm{H}$ (eds) Cetacean societies: field studies of dolphins and whales. University of Chicago Press, Chicago, IL, p 65-87

Williams JA, Dawson SM, Slooten E (1993) The abundance and distribution of bottlenosed dolphins (Tursiops truncatus) in Doubtful Sound, New Zealand. Can J Zool 71: 2080-2088

Williams BK, Nichols JD, Conroy MJ (2002) Estimating abundance for closed populations with mark-recapture methods. In: Analysis and management of animal populations. Academic Press, London, p 289-332

Wilson B, Hammond PS, Thompson PM (1999) Estimating size and assessing trends in coastal bottlenose dolphin population. Ecol Appl 9:288-300

Submitted: May 4, 2010; Accepted: July 8, 2011

Proofs received from author(s): September 8, 2011 